\title{
Caval filters in intensive care: a retrospective study
}

This article was published in the following Dove Press journal:

Drug Design, Development and Therapy

6 November 2014

Number of times this article has been viewed

\section{F Ferraro' \\ TL Di Gennaro' \\ A Torino' \\ J Petruzzi' \\ A d'Elia' \\ P Fusco' \\ R Marfella ${ }^{2}$ \\ B Lettieri'}

'Department of Anesthesiological, Surgical and Emergency Sciences,

${ }^{2}$ Department of Geriatrics

and Metabolic Diseases, Second

University of Naples, Naples, Italy

Video abstract

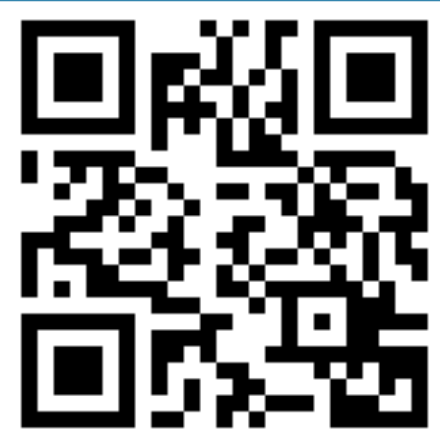

Point your SmartPhone at the code above. If you have a QR code reader the video abstract will appear. Or use:

http://dvpr.es//xhKbk0

Correspondence: $F$ Ferraro

Corso Vittorio Emanuele, 649/c - 80121,

Napoli, Italy

$\mathrm{Tel}+39081660973$

Fax +390815666622

Email fausto.ferraro@unina2.it
Aim: To evaluate the effectiveness of a caval vein filter (CVF) peri-implant monitoring protocol in order to reduce pulmonary embolism (PE) mortality and CVF-related morbidity.

Background: The reduction in mortality from PE associated with the use of CVF is affected by the risk of increase in morbidity. Therefore, CVF implant is a challenging prophylactic or therapeutic option. Nowadays, we have many different devices whose rational use, by applying a strict peri-implant monitoring protocol, could be safe and effective.

Materials and methods: We retrospectively studied 62 patients of a general Intensive Care Unit (ICU) scheduled for definitive, temporary, or optional bedside CVF implant. A periimplant monitoring protocol including a phlebocavography, an echo-Doppler examination, and coagulation tests was adopted.

Results: In our study, no thromboembolic recurrence was registered. We implanted 48 retrievable and only 20 definitive CVFs. Endothelial adhesion (18\%), residual clot (5\%), cranial or caudal migration $(6 \%)$, microbial colonization of the filter in the absence of clinical signs of infection $(1 \%)$, caval thrombosis $(1 \%)$, and pneumothorax $(1 \%)$ were reported. Deep-vein thrombosis (DVT) was reported $(8 \%)$ as early complication. All patients with DVT had a temporary or optional filter implanted. However, in our cohort, definitive CVFs were reserved only to $32 \%$ of patients and they were not associated with DVT as complication.

Conclusion: CVF significantly reduces iatrogenic PE without affecting mortality. Generally, ICU patients have a transitory thromboembolic risk, and so the temporary CVF has been proved to be a first-line option to our cohort. A careful monitoring may contribute to a satisfactory outcome in order to promote CVF implant as a safe prophylaxis option.

Keywords: caval vein filter, thromboembolic disease, pulmonary embolism

\section{Introduction}

Thromboembolic disease (TED) is a very common cause of death. ${ }^{1-3}$ The diagnosis appears undervalued, because it is often formulated in postmortem examination. ${ }^{4,5}$ Clinical suspect imposes a more careful diagnosis and the research of permanent or transitory risk factors, in order to establish prophylaxis and therapy. ${ }^{6-24}$ According to the literature, treatment or prophylaxis with the interruption of the inferior caval vein seems to deal with a reduction in mortality but not in morbidity, especially in the case of some caval vein filter (CVF) implants. ${ }^{25,26}$ High-risk patients (ie, affected by proximal deep-vein thrombosis [DVT]) who underwent CVF implant reported benefits in pulmonary embolism (PE) prevention. However, this was often counterbalanced by an excess of recurrent DVT, without any difference in mortality at two years. ${ }^{7}$

The first CVF was developed by Mobin-Uddin in the 1960s. Its specific function was to stop the shower emboli through the inferior caval vein not to jeopardize the microcircle. This definitive caval filter (DCF) was surgically placed across a central vein. Its mechanism of action was "to sieve" the blood flow, with a high transfilter gradient. This dealt with important complications (ie, caval vein thrombosis, 
elephantiasis). ${ }^{12}$ In the 1970 s, Greenfield introduced a new filter. This was formed by steel filaments joined together in a radial and convergent way in order to form a cone that was structurally different from the one developed by Mobin-Uddin. Greenfield boasted a hydrodynamic filtering with a notable reduction of the resistances to the flow and a reduction of complications. The vortexes created by the filter would turn the shower emboli toward the center of the cone. The blood flow facilitates their fragmentation, maintaining a notable efficiency, despite the low-pressure gradient transfilter and a consequent reduction of complications. ${ }^{27,28}$ In the 1980s, some new hydrodynamic filters were developed, thanks to the introduction of high biocompatible material. These devices were characterized by lower French size in order to be easily introduced in local anesthesia. The first temporary metal filter (with an estimated permanence time of only 3-4 days) was introduced too. It was indicated for the protection of surgical thrombectomy and thrombolysis. Nowadays, two kinds of CVFs are available: DCFs and retrievable caval filters (RCFs), percutaneously implanted by small French size technique. ${ }^{29-39}$ DCFs represent the techevolution of the partial interruption of caval inferior vein. Indications to the implant of such devices are recurrent PE in spite of anticoagulant therapy, permanent contraindication to a necessary anticoagulant therapy.

RCFs are divided into temporary caval filters (TCFs) and optional caval filters (OCFs). TCFs are used in patients with thromboembolic risk limited to the time of illness such as the protected thrombolysis in TED, surgically protected thrombectomy, pharmacologically impossible or ineffective therapy (conditions of transitory risk), and high-risk pathology. ${ }^{40-46}$ We consider the application of TCF important for anesthesia and Intensive Care Unit (ICU) patients too. OCFs are indicated for a patient with the intent of temporariness. ${ }^{47}$ These filters can be removed after the corresponding period of cautious time, but they are able to be left in situ permanently.

\section{Purpose}

The purpose of this study was to evaluate the effectiveness of a CVF peri-implant monitoring protocol in order to reduce $\mathrm{PE}$ mortality and CVF-related morbidity. Furthermore, we aim at contributing through our study to a more careful identification of indications to DCF, TCF, and OCF implants.

\section{Materials and methods}

In our retrospective study, all patients who underwent implantation of a CVF in a general ICU of the University Hospital from December 1993 to December 2013 were studied. We registered implantation of 68 filters (20 DCFs, 45 TCFs, and 3 OCFs) for a total of 62 patients ( 34 males and 28 females, median age $48 \pm 20.8$ years). This study was conducted according to the principles established in the Declaration of Helsinki with the approval of the ethics committee of the Second University of Naples. According to indications and contraindications, we implanted DCFs, TCFs, and OCFs. In particular, two types of TCFs were used: at brief (7-10 days) or middle (6-12 weeks) permanence. The former had an external fixed catheter to the point of cutaneous emergency, which allowed the introduction of infusions directly into the filter (Prolyser ${ }^{\circledR}$; Cordis). The latter (ie, Tempofilter II) had a subcutaneous fixing catheter implantable system (Table 1).

The permanence time of CVF was related to patient's illness, device model, and the incidence of any complications (ie, endothelial adhesion enclosing the filter and preventing the following removal, vulnerability of the catheter to infections from the outside).

To our cohort, medical anticoagulant therapy was always contraindicated or not effective. Concerning patients with DVT, our population included $54 \%$ of medical patients (one of them with systemic erythematosus lupus), 24\% of cancer patients in medical treatment, $3 \%$ of cancer patients in surgical treatment, and $18 \%$ of patients undergoing a perioperative prophylaxis.

Indications to DCF implant were neurosurgery $(1 \delta$ patient who first was implanted a TCF), orthopedic surgery $(3 \hat{\jmath})$, trauma ( $1 \hat{\delta}$ patient who first was implanted a TCF), chronic obliterans arteriopathy $\left(2{ }^{\Uparrow}\right)$, and DVT $\left(7 \circ, 6{ }^{\lambda}\right)$. TCFs were implanted in patients reporting positive anamnesis for pregnancy $(5)$, neurosurgery/stroke $(1 \hat{\jmath})$, orthopedic

Table I Filter models

Permanent filters
ANGIOCOR ADI ${ }^{\circledR}$
Cordis "KEEPER" (cod $463-850 / 463-8 I 0)=$ AFI (fem)/ASI (giug):
This filter is designed for vena cava of a diameter inferior to $35 \mathrm{~mm}$
Antheor DC: This filter is designed for vena cava of a diameter inferior
to $30 \mathrm{~mm}$
Antheor DC4 ${ }^{\circledR}$ : megacave
Braun LGM-Vena Tech
Braun LPI ${ }^{\circledR}$
Temporary filters
Cordis temporary vena cava filter Prolyser
Braun LGT ${ }^{\circledR}$ : The maximum time in situ is 10 days
Braun Tempofilter II: The maximum time in situ is 6 weeks
Antheor TC
Optional filters
ALN
SNF ${ }^{\circledR}$ (Simon-Nitinol Filter)


surgery $(2 \hat{\jmath}, 1 \uparrow)$, DVT $(9 \circ, 11 \hat{\jmath})$, trauma $(3 \uparrow, 11 \hat{\jmath})$. The indications to OCF implant were stroke (1+) and DVT $\left(2{ }^{\top}\right)$ (Tables 2 and 3). Filters were placed percutaneously by the anesthesiologist at the bedside in the ICU with the patient under local anesthesia. Patients were premedicated with atropine $0.01 \mathrm{mg} / \mathrm{kg}$ intravenously and then locally anesthetized by administration of $0.2 \%$ of lidocaine $1 \mathrm{mg} / \mathrm{kg}$ subcutaneously. Heart rate (ECG), oxygen saturation, and arterial blood pressure were continuously monitored. An image intensifier, previous administration of contrast media through the right internal jugular vein, was used.

The post CVF implant monitoring was very important, especially for patients receiving TCFs. ${ }^{48-52}$ In order to prevent complications, we focused first on clinical signs and filtration conditions. Our postoperative monitoring protocol consisted of an echo-Doppler every 3-5 days and a phlebocavography before and after implantation and before removing the filter. An invasive hemodynamic monitoring was adopted in the case of TCF implant through the inferior and superior caval vein pressure evaluation: an increase of the differential caval vein pressure $(>3 \mathrm{mmHg})$ was considered, according to our protocol, as an early sign of caval thrombosis. Coagulation tests (platelet [PLT], activated partial thromboplastin time [aPTT], prothrombin time [PT], international normalized ratio (INR), fibrinogen, and antithrombin [AT] III) were monitored every 12 hours to 24 hours. In the case of intravenous heparin therapy, the aPTT control was performed every 4 hours, maintaining the value $>1.5$ normal aPTT. Before discharge, all patients had undergone a clinical examination, an abdominal X-ray, and an ultrasound evaluation.

An abdominal radiography at days 1 and 7 and then yearly after placement was performed for the follow-up after the

Table 2 Implanted filters

\begin{tabular}{|c|c|c|}
\hline DCF & Total $n=20$ & Implantation period \\
\hline Antheor DC4 ${ }^{\circledR}$ & $\mathrm{n}=2$ & \\
\hline ANGIOCOR ADI ${ }^{\circledR}$ & $\mathrm{n}=2$ & \\
\hline Braun LGM-Vena Tech & $n=9$ & \\
\hline Braun LPI ${ }^{\circledR}$ & $\mathrm{n}=7$ & \\
\hline $\mathrm{TCF}$ & Total $n=45$ & Mean 23.49 (range 3-60) days \\
\hline Cordis Prolyser & $\mathrm{n}=14$ & \\
\hline Braun Tempofilter II & $n=27$ & \\
\hline Antheor TC & $n=3$ & \\
\hline Braun LGT ${ }^{\circledR}$ & $\mathrm{n}=\mathrm{I}$ & \\
\hline OCF & Total $n=3$ & \\
\hline $\mathrm{ALN}^{\circledR}$ & $\mathrm{n}=2$ & \\
\hline $\mathrm{SNF}^{\circledR}$ & $n=1$ & \\
\hline
\end{tabular}

Abbreviations: DCF, definitive caval filter; TCF, temporary caval filter; OCF, optional caval filter; SNF, Simon-Nitinol filter. implantation of the DCF. Our study in particular, aimed at evaluating short-term (1-3 months after the implantation) and long-term (3 months to 20 years) complications.

\section{Results}

In our study, no thromboembolic recurrence was registered. DCFs implant dealt with caudal migration (5\%) and cranial migration (10\%) within $3 \mathrm{~cm}$, without filter inclination on its axis (tilting) and, then, without loss of their function.

TCF implant dealt with the following complications: mild endothelial adhesion (18\%) without any interference with the filter removal and the patient care; caval thrombosis (2.27\%) pharmacologically treated with local thrombolysis; residual clot (diameter $<1 \mathrm{~cm}$ ) in the basket $(6.8 \%)$; and microbial colonization of the filter in the absence of clinical signs of infection (2.27\%).

Concerning OCFs ( $\mathrm{n}=3)$, our study reported the following complications: mild endothelial adhesion without any consequences (100\%); microbial colonization of the filter in the absence of clinical signs of infection (33.3\%); cranial migration with filter inclination $>15^{\circ}$ on its axis (tilting); and loss of filtering function (33.3\%). A filter substitution had been performed to treat this last complication, and

Table 3 Patient characteristics

\begin{tabular}{ll}
\hline Patients & $\mathrm{n}=62$ \\
Sex (female/male) & $28 / 34$ \\
Age (years), median (range) & 47.84 (I5-86) \\
Indications to DCF & \\
$\quad$ Chronic obliterans arteriopathy & 2 \\
$\quad$ DVT & 13 \\
Trauma & $\mathrm{I}$ \\
$\quad$ Orthopedic surgery & 3 \\
Neurosurgery & $\mathrm{I}$ \\
Total DCF & $20^{*}$ \\
Indications to TCF & \\
$\quad$ DVT & $20^{\#}$ \\
Trauma & $14^{\#}$ \\
Orthopedic surgery & 3 \\
Neurosurgery & $\mathrm{I}$ \\
Pregnancy & 5 \\
Total TCF & 45 \\
Indications to OCF & \\
DVT & 2 \\
Stroke & $\mathrm{I}$ \\
Total OCF & 3 \\
\hline Notes &
\end{tabular}

Notes: *Two patients first underwent the implant of a temporary filter (Cordis Prolyser/Braun LGT ${ }^{\circledast}$ ), which was later replaced with a definitive one (Antheor DC4 ${ }^{\otimes} /$ Angiocor ADI). "One patient underwent first a temporary caval vein filter implant, which was later replaced with a definitive one; one patient underwent two times the substitution from a TCF to another TCF; one patient underwent a substitution into an OCF. Two patients underwent a filter substitution respectively into a definitive (ANGIOCOR ADI ${ }^{\circledR}$ ) and a temporary (Cordis Prolyser) caval vein filter.

Abbreviations: DCF, definitive caval filter; DVT, deep vein thrombosis; TCF, temporary caval filter; OCF, optional caval filter. 
pneumothorax consequently appeared at the third day after implantation. It was quickly resolved (1 patient).

DVT incidence was $8 \%$ (5/62 patients), reported as shorttime complication. Just for one patient (1.6\%), it was reported as late complication, because the incidence was 2 years after filter implantation. However, it was treated and resolved without consequences. All patients with DVT had a TCF or OCF implanted. In our cohort, DCFs were not associated with DVT as complication (Table 4).

\section{Discussion}

The Department of Health in England in 2009 considered deaths from $\mathrm{PE}$ as preventable deaths. ${ }^{23}$ It could be an exciting challenge to significantly reduce $\mathrm{PE}$ incidence by increasing awareness, thromboprophylaxis, and early mobilization. In 2011 Kopcke et al, in fact, focused on a substantial reduction in the hospital death rates due to PE from around 10\% to $1 \%$ all over the last 30 years. Furthermore, the authors stated that there is a limited potential for prevention of PE mortality through greater use of CVF if the accepted criteria for filter placement are applied. ${ }^{4}$

In our study, a strict peri-implant but, in particular, a postimplant monitoring protocol (ie, temporized echoDoppler with differential caval vein pressure evaluation, phlebocavography, coagulation tests, abdominal X-ray) deals with the efficacy of PE prophylaxis and treatment with CVF. That is, a reduction in mortality from $P E$ and morbidity from CVF implant was observed in our retrospective study. Sixty-two patients were implanted a total amount of $68 \mathrm{CVF}$ ( $n=20, D C F ; n=48, R C F)$. Thromboembolic recurrence did not occur in any patient. Mild endothelial adhesion occurred without any interference with filter function and removal; a few cases of filter migration were registered, but only in one patient, a filter substitution became necessary. Just one episode of caval thrombosis and one episode of residual clot were reported after TCF implant. Microbial colonization of the filter in the absence of clinical signs of infection occurred in two patients.

DVT incidence occurred only in patients with RCF implants $(8 \%)$ in spite of what was reported in literature. The PREPIC randomized trial in fact reported an initial small reduction in $\mathrm{PE}$, the absence of a later significant reduction in mortality associated with a higher incidence of proximal DVT in patients with permanent CVF implant., ${ }^{4,53}$ However, these data should be carefully analyzed and related to the concomitant anticoagulant therapy practiced. For this reason, the indications to DCF implants diminish, because of the shortness of efficacy proven (only for the first 3 months of illness). ${ }^{54}$ Nevertheless, our study did not report any increase of occurrence in thrombotic disease in the case of permanent filter implant. Our results are consistent with the findings of Vaziri et al dealing with PE prophylaxis both by RCF and chemotherapeutics in bariatric surgery. The experience of Vaziri et al described a lower incidence of DVT, the absence of clinical episodes of PE and, in spite of a mean time to filter retrieval of $200 \pm 131$ days, a lower incidence of filter complications with a successful end easy retrieval. All bariatric patients with a prior history of venous thromboembolism (VTE), hypercoagulable disorder, body mass index $\geq 55 \mathrm{~kg} / \mathrm{m}^{2}$, marginal pulmonary reserve, and severe immobility were considered to be at higher risk for postoperative VTE and underwent RCF placement in association with standard chemoprophylaxis. ${ }^{55}$

Our data suggest Tempofilter II implant for transitory risk because of its longer time of permanence in situ. In most cases, we recognized the presence of the transitory risk in the genesis of the PE (surgical, traumatized, and pregnant patients), which was TCF implant in $70 \%$ of the

Table 4 Filter-related complications

\begin{tabular}{|c|c|c|c|}
\hline Filter & Complications & Number of patients & Implantation period \\
\hline \multirow[t]{2}{*}{$\mathrm{DCF}$} & Cranial migration $(2 \mathrm{~cm})$ & 2 & 6-68 months \\
\hline & Caudal migration $(3 \mathrm{~cm})$ & 1 & \\
\hline \multirow[t]{5}{*}{ TCF } & Caval thrombosis & 1 & $4-28$ days $(\mid 8.5 \pm 8.5)$ \\
\hline & Residual clot & 3 & \\
\hline & Endothelial adhesion & 8 & \\
\hline & Microbial colonization of the filter in absence of clinical signs of infection & 1 & \\
\hline & DVT & 4 & \\
\hline \multirow[t]{5}{*}{ OCF } & Cranial migration & 1 & $3-48$ days $(25.3 \pm 12)$ \\
\hline & Endothelial adhesion & 3 & \\
\hline & Microbial colonization of the filter in absence of clinical signs of infection & I & \\
\hline & Pneumothorax & I & \\
\hline & DVT & 1 & \\
\hline
\end{tabular}

Abbreviations: DCF, definitive caval filter; TCF, temporary caval filter; DVT, deep vein thrombosis; OCF, optional caval filter. 
cases. ${ }^{14,15,19,42-44}$ The indications to TCFs both for prophylaxis and therapy of the TED increase despite the Antithrombotic Therapy and Prevention of Thrombosis, 9th ed (AT9) ${ }^{56}$ suggesting not to use these devices for primary VTE prevention in patients with major trauma, general and abdominal-pelvic surgery, or major orthopedic surgery. Acute DVT of the leg, such as acute PE, is recommended to be treated with CVF only in the case of contraindication to anticoagulation (AT9, grade 1B). The AT9 suggest a conventional course of anticoagulant therapy as soon as the risk of bleeding in these patients resolves. The rationale of contemporary anticoagulant administration would not seem to be linked to the permanent caval filter implant. ${ }^{56}$ Despite the presence of such guidelines, the literature background continue to get more and more opinions of disagreement may be because of the difficulty in sharing of opinions and experiences. Rajasekhar et $\mathrm{al}^{57}$ underlined the presence of measurement and/or publication bias in all observational studies examined to publish their systematic review. According to the meta-analysis of observational studies in epidemiology (MOOSE) guidelines and the Newcastle Ottawa scale for quality assessment, they found the rate of PE to be statistically lower in the presence rather than in the absence of inferior CVF implant in trauma patients. These data remain biased because of the lack of contemporary pharmacologic prophylaxis described in the analyzed studies. ${ }^{57}$ Thus, PE is thought to be the third major cause of death after trauma in patients surviving longer than 24 hours after the onset of injury, a common line of conduct remains still unclear. ${ }^{47}$ The enthusiasm is divided on the advantages of TCFs at middle permanence, but we are so far to dispose of a device and of an applicatory control without risk. The excellent outcome was provided by a careful monitoring. This aspect limits the diffusion of the method that, otherwise, is burdened by an increase of the failures. ${ }^{58-67}$

\section{Conclusion}

Our study proves the effectiveness of CVFs in TED, when anticoagulant therapy is contraindicated or not effective. Temporary risk factors play an important role in $\mathrm{PE}$ and, in particular, deal both on the increased and decreased indications for TCF and DCF implants, respectively. An appropriate laboratory and echo-Doppler monitoring allowed us to extend safely the time of permanence in situ of TCF. In the past few years, the indications for the use of the CVF underwent a critical revision accompanied by a therapeutic restriction especially for the DCF. The indications for the TCF show an increasing extension with regard to the coverage of the transitory risk, where the time of permanence of the RCF is increased to 6 weeks. Thanks to the accurate monitoring, TCF permanence in situ has been longer, according to clinical needs. A lot of conditions of transitory risk (ie, major trauma, pregnancy, orthopedic surgery, major surgery) have a time of protection demanding longer than the maximum time of filtration of the first removable filters. We proved the time of permanence in situ among the TCFs and the OCFs to be significantly different (days: $18.5 \pm 8.5$ vs $25.2 \pm 11.6$, respectively). We did not prefer to use DCF because of both the limited indications in our population and the lack of literature recommendation.

Among TCFs, the Tempofilter II allows a longer protection and a simple management but is contraindicated for thrombolysis.

More polycentric clinical trials are needed to better evaluate indications for caval filtration in order to give this approach enhanced safety, efficacy, and propagation.

\section{Disclosure}

The authors report no conflicts of interest in this work.

\section{References}

1. White RH. The epidemiology of venous thromboembolism. Circulation. 2003;107:1-4.

2. Stein PD. Incidence of acute pulmonary embolism in a general hospital. Chest. 1999;116:909-913.

3. Giuntini C, Di Rocco G, Marini C, Melillo E, Palla A. Pulmonary embolism: epidemiology. Chest. 1995;107:35-39.

4. Kopcke D, Harryman O, Benbow EW, Hay C, Chalmers N. Mortality from pulmonary embolism is decreasing in hospital patients. $J R$ Soc Med. 2011;104(8):327-331.

5. Lau G. Pulmonary thromboembolism is not uncommon - result and implications of a five-year study of 116 necropsies. Ann Acad Med Singapore. 1995;24:356-365.

6. Kearon C, Hirsh J. The diagnosis of pulmonary embolism. Haemostasis. 1995;25:72-86.

7. Tapson VF. Advances in the diagnosis and treatment of acute pulmonary embolism. F1000 Med Rep. 2012;4:9.

8. Goldhaber SZ, Morpurgo M. Diagnosis, treatment and prevention of pulmonary embolism. Report of the WHO/International Society and Federation of Cardiology Task Force. JAMA. 1992;268:1727-1733.

9. Abdel-Razeq H, Mansour A, Ismael Y, Abdulelah H. Inferior vena cava filters in cancer patients: to filter or not to filter. Ther Clin Risk Manag. 2011;7:99-102.

10. Goldhaber SZ. Modern treatment of pulmonary embolism. Eur Respir J. 2002;19:22S-27S.

11. Greenfield LJ, Proctor MC. Current indications for caval interruption: should they be liberalized in view of improving technology? Semin Vasc Surg. 1996;9:50-58.

12. Winchell RJ, Hoyt DB, Walsh JC, Simons RK, Eastman AB. Risk factors associated with pulmonary embolism despite routine prophylaxis implications for improved protection. J Trauma. 1994;37:600-606.

13. Nunn CR, Neuzil D, Naslund T, et al. Cost-effective method for bedside insertion of vena caval filters in trauma patients. J Trauma. 1997;43: $752-758$.

14. Rogers FB, Shackford SR, Wilson J, Ricci MA, Morris CS. Prophilactic vena cava filter insertion in severely injured trauma patients: indications and preliminary results. $J$ Trauma. 1993;35:637-642. 
15. Kawamata K, Chiba Y, Tanaka R, Higashi M, Nishigami K. Experience of temporary inferior vena cava filters inserted in the perinatal period to prevent pulmonary embolism in pregnant women with deep vein thrombosis. J Vasc Surg. 2005;41:652-656.

16. Rosen MP, Porter DH, Kim D. Reassessment of vena caval filter use in patients with cancer. J Vasc Interv Radiol. 1994;5:501-506.

17. Hoppe H, Kaufman JA, Barton RE, et al. Safety of inferior vena cava filter retrieval in anticoagulated patients. Chest. 2007;132:31-36.

18. Yonezawa K, Yokoo N, Yamaguchi T. Effectiveness of an inferior vena caval filter as a preventive measure against pulmonary thromboembolism after abdominal surgery. Surg Today. 1999;29:821-824.

19. Carlin AM, Tyburski JG, Wilson RF, Steffes C. Prophylactic and therapeutic inferior vena cava filters to prevent pulmonary emboli in trauma patients. Arch Surg. 2002;137:521-527.

20. Lossef SV, Barth KH. Outcome of patients with advanced neoplastic disease receiving vena caval filters. J Vasc Interv Radiol. 1995;6: 273-277.

21. Streiff MB. Vena caval filters: a review for intensive care specialists. J Intensive Care Med. 2003;18:59-79.

22. Sing RF, Jacobs DG, Heniford BT. Bedside insertion of inferior vena cava filters in the intensive care unit. J Am Coll Surg. 2001;192:570-575.

23. Arya R, Paneesha S, McManus A, et al. More on thromboprophylaxis: quantifying risk for venous thromboembolism. Thromb Haemost. 2009; 101(4):791-794

24. Athanasoulis CA, Kaufman JA, Halpern EF, Waltman AC, Geller SC, Fan CM. Inferior vena caval filters: review of a 26-year single-center clinical experience. Radiology. 2000;216:54-66.

25. Mohan CR, Hoballah JJ, Sharp WJ, Kresowik TF, Lu CT, Corson JD. Comparative efficacy and complications of vena caval filters. $J$ Vasc Surg. 1995;21:235-246.

26. McLoughlin RF, Sirkis H, So CB, Raber EL, Saliken J, Gray RR. Severity of disease score as a predictor of mortality after caval filter insertion. J Vasc Interv Radiol. 1995;6:715-719.

27. Greenfield LJ, Michna BA. Twelve-year clinical experience with the Greenfield vena caval filter. Surgery. 1988;104:706-712.

28. Rosenthal D, McKinsey JF, Levy AM, et al. Use of the Greenfield filter in patients with major trauma. Cardiovasc Surg. 1994;2:52-55.

29. Kinney TB. Update on inferior vena cava filters. J Vasc Interv Radiol. 2003; $14: 425-440$.

30. Greenfield LJ. Selecting a vena caval device. Chest. 1993;105:1632.

31. Streiff MB. Vena caval filters: a comprehensive review. Blood. 2000; 95:3669-3677.

32. Ingber $\mathrm{S}$, Geerts $\mathrm{WH}$. Vena caval filters: current knowledge, uncertainties and practical approaches. Curr Opin Hematol. 2009;16(5):402-406.

33. Lam RC, Bush RL, Lin PH, Lumsden AB. Early technical and clinical results with retrievable inferior vena caval filters. Vascular. 2004;12: 233-237.

34. Binkert CA, Bansal A, Gates JD. Inferior vena cava filter removal after 317-day implantation. J Vasc Interv Radiol. 2005;16:395-398.

35. Bovyn G, Catroux B, Lenot B, Marjot-Zimbacca F, Boujonnier C, Lavaud F. Value of a long duration temporary caval filter in critical thrombo-embolic situations. Ann Fr Anesth Reanim. 2003;22:763-764.

36. Bovyn G, Ricco JB, Reynaud P, Le Blanche AF, European Tempofilter II Study Group. Long-duration temporary vena cava filter: a prospective 104-case multicenter study. J Vasc Surg. 2006;43:1222-1225.

37. Millward SF, Peterson RA, Moher D, et al. LGM (Vena Tech) vena caval filter: experience at a single institution. J Vasc Interv Radiol. 1994; 5:351-356.

38. Murray R. Initial experience in humans with a new retrievable inferior vena cava filter. Radiology. 2002;225:835-844.

39. Kaufman JA. Retrievable vena cava filters. J Vasc Interv Radiol. 2004; 7:96-104.

40. Scholz KH, Just M, Buchwald AB, Werner GS, Stille-Siegener M, Kreuzer H. Experiences with temporary vena cava filters in 114 at-risk patients with thrombosis or thromboembolism. Dtsch Med Wochenschr. 1999;124:307-313.
41. Bovyn G, Gory P, Reynaud P, Ricco JB. The Tempofilter: a multicenter study of a new temporary caval filter implantable for up to six weeks. Ann Vasc Surg. 1997;11:520-528.

42. Cheung MC, Asch MR, Gandhi S. Kingdom JC. Temporary inferior vena caval filter use in pregnancy. J Thromb Haemost. 2005;3:1096-1097.

43. Offner PJ, Hawkes A, Madayag R, Seale F, Maines C. The role of temporary inferior vena cava filters in critically ill surgical patients. Arch Surg. 2003;138:591-595.

44. Allen TL, Carter JL, Morris BJ, Harker CP, Stevens MH. Retrievable vena cava filters in trauma patients for high-risk prophylaxis and prevention of pulmonary embolism. Am J Surg. 2005;189:656-661.

45. Caronno R, Piffaretti G, Tozzi M. Mid-term experience with the ALN retrievable inferior vena cava filter. Eur J Vasc Endovasc Surg. 2006;32: 596-599.

46. Ponchon M, Goffette P, Hainaut P. Temporary vena caval filtration. Preliminary clinical experience with removable vena cava filters. Acta Clin Belg. 1999;54:223-228.

47. Aryafar H, Kinney TB. Optional inferior vena cava filters in the trauma patient. Semin Intervent Radiol. 2010;27(1):68-80.

48. Crochet DP, Brunel P, Trogrlic S, Grossetëte R, Auget JL, Dary C. Long-term follow-up of Vena Tech-LGM filter: predictors and frequency of caval occlusion. J Vasc Interv Radiol. 1999;10:137-142.

49. Greenfield LJ, Rutherford RB. Recommended reporting standards for vena caval filter placement and patient follow-up. Vena Caval Filter Consensus Conference. J Vasc Interv Radiol. 1999;10:1013-1019.

50. Matchett WJ, Jones MP, McFarland DR, Ferris EJ. Suprarenal vena caval filter placement: follow-up of four filter types in 22 patients. J Vasc Interv Radiol. 1998;9:588-593.

51. Millward SF, Grassi CJ, Kinney TB, et al. Reporting standards for inferior vena caval filter placement and patient follow-up: supplement for temporary and retrievable/optional filters. J Vasc Interv Radiol. 2005; 16:441-443

52. Wojcik R, Cipolle MD, Fearen I, Jaffe J, Newcomb J, Pasquale MD. Long-term follow-up of trauma patients with a vena caval filter. J Trauma. 2000;49:839-843.

53. PREPIC Study Group. Eight-year follow-up of patients with permanent vena cava filters in the prevention of the pulmonary embolism: the PREPIC (Prevention du Risque d'Embolie Pulmonaire par Interruption Cave) randomized study. Circulation. 2005;112:416-422.

54. Decousus H, Leizorovicz A, Parent F, et al. A clinical trial of vena cava filters in the prevention of pulmonary embolism in patients with proximal deep vein thrombosis. N Engl J Med. 1998;338:449-515.

55. Vaziri K, Devin Watson J, Harper AP, et al. Prophylactic inferior vena cava filters in high-risk bariatric surgery. Obes Surg. 2011;21(10): $1580-1584$

56. Guyatt GH, Akl EA, Crowther M, et al. Executive Summary: Antithrombotic Therapy and Prevention of Thrombosis, 9th ed: American College of Chest Physicians, Evidence-based clinical practice guidelines. Chest. 2012;141(2_suppl):1S.

57. Rajasekhar A, Lottenberg R, Lottenberg L, Liu H, Ang D. Pulmonary embolism prophylaxis with inferior vena cava filters in trauma patients: a systematic review using the meta-analysis of observational studies in epidemiology (MOOSE) guidelines. J Thromb Thrombolysis. 2011; 32(1):40-46.

58. David W, Gross WS, Colaiuta E, Gonda R, Osher D, Lanuti S. Pulmonary embolus after vena cava filter placement. Am Surg. 1999;65: 341-346.

59. Ferraro F, Iannuzzi E, Mocavero PE, Papa A, Galluccio V. Complications in temporary percutaneous caval interruption. Clin Intensive Care. 1995;6:31.

60. Bianchini AU, Mehta SN, Mulder DS, Barkun AN, Mayrand S. Duodenal perforation by a Greenfield filter: endoscopic diagnosis. $\mathrm{Am}$ J Gastroenterol. 1997;92:686-687.

61. Putterman D, Niman D, Cohen G. Aortic pseudoaneurysm after penetration by a Simon nitinol inferior vena cava filter. $J$ Vasc Interv Radiol. 2005; 16:535-538. 
62. Ritchie AJ, Mithchell L, Forty J. Migration of a vena caval filter to the pulmonary artery. Br J Surg. 1995;82:207.

63. Vaislic C, Clerc P, Her B, So NW, Setin J. Migration of an Antheor filter in the pulmonary artery. A case. Presse Med. 1993;22:717-723.

64. Rossi P, Arata FM, Bonaiuti P, Pedicini V. Fatal outcome in atrial migration of the tempofilter. Cardiovasc Intervent Radiol. 1999;22: $227-231$.
65. Tardy B, Page Y, Zeni F. Acute thrombosis of vena cava filter with a clot above the filter. Successful treatment with low-dose urokinase. Chest. 1994;106:1607-1609.

66. Girard P, Stern JB, Parent F. Medical literature and vena cava filters. So far so weak. Chest. 2002;122:963-967.

67. Haire WD. Vena caval filters for the prevention of the pulmonary embolism. N Engl J Med. 1998;338:463-464.

\section{Publish your work in this journal}

Drug Design, Development and Therapy is an international, peerreviewed open-access journal that spans the spectrum of drug design and development through to clinical applications. Clinical outcomes, patient safety, and programs for the development and effective, safe, and sustained use of medicines are a feature of the journal, which has also been accepted for indexing on PubMed Central. The manuscript management system is completely online and includes a very quick and fair peer-review system, which is all easy to use. Visit http://www.dovepress.com/testimonials.php to read real quotes from published authors.

Submit your manuscript here: http://www.dovepress.com/drug-design-development-and-therapy-journal 